\title{
Inhibition of Cap-initiation complexes linked to a novel mechanism of elF4G depletion in acute myocardial ischemia
}

\author{
EP Connolly ${ }^{1}$, V Thuillier ${ }^{2}$, D Rouy ${ }^{2,3}$, G Bouétard $^{2}$ and \\ RJ Schneider*,1 \\ ${ }^{1}$ Department of Microbiology, New York University School of Medicine, 550 First \\ Avenue, New York, NY 10016, USA \\ 2 Aventis-Centelion SAS, 72 à 82 rue Léon Geffroy, Vitry sur Seine 94400 , \\ France \\ 3 Current address: CRP-Sante, L-1417, Luxembourg \\ * Corresponding author: RJ Schneider, Department of Microbiology, NYU \\ School of Medicine, 550 First Avenue, New York, NY 10016, USA. \\ Tel: +1 212263 6006; Fax: + 1212263 8276; \\ E-mail: schner01@med.nyu.edu
}

Received 15.6.05; revised 01.12.05; accepted 02.12.05; published online 27.1.06 Edited by RA Knight

\begin{abstract}
Translational control in the rat heart was characterized during acute myocardial ischemia introduced by left coronary artery ligature. Within $10 \mathrm{~min}$ of ischemia, eukaryotic (elF)4E binds to its negative regulator, elF4E-binding protein-1 (4E-BP1), but the levels of 4E-BP1 are insufficient to disrupt capdependent mRNA initiation complexes. However, by $1 \mathrm{~h}$ of ischemia, the abundance of the cap-initiation complex protein eIF4G is reduced by relocalization into TIAR protein complexes, triggering 4E-BP1 sequestration of elF4E and disruption of cap-dependent mRNA initiation complexes. As the heart begins to fail at $6 \mathrm{~h}$, proteolysis of elF $4 \mathrm{G}$ is observed, resulting in its depletion and accompanied by limited destruction of 4E-BP1 and elF4E. elF4G proteolysis and modest loss of 4E-BP1 are associated with caspase-3 activation and induction of cardiomyocyte apoptotic and necrotic death. Acute heart ischemia therefore downregulates cap-dependent translation through elF4E sequestration triggered by elF4G depletion.

Cell Death and Differentiation (2006) 13, 1586-1594.

doi:10.1038/sj.cdd.4401854; published online 27 January 2006
\end{abstract}

Keywords: protein synthesis; translational control; myocardial ischemia; ischemia

Abbreviations: elF, eukaryotic initiation factor; eEF, eukaryotic elongation factor; 4E-BP1, elF4E-binding protein-1; mTOR, mammalian target of rapamycin (kinase); LV, left ventricle; RV, right ventricle

\section{Introduction}

Protein synthesis is highly regulated and is suppressed during a variety of cell stresses, including thermal, physical and metabolic stresses as well as during viral infection. ${ }^{1-5}$ Ischemia is a severe metabolic stress, which leads to energy depletion and downregulation of mRNA translation. ${ }^{6-8}$ The mechanisms underlying protein synthesis inhibition during ischemia have been extensively studied in models of both transient focal and global cerebral ischemia. ${ }^{9-13}$ In contrast, very little research has been conducted to understand the mechanisms of translation inhibition during myocardial ischemia. $^{6,14}$

Regulation of protein synthesis can occur through a number of different mechanisms involving both initiation and elongation. Translation initiation is regulated most commonly during two different processes, the recruitment of mRNA to ribosomes and the availability of the ternary complex (elF2GTP-Met-tRNA) for initiation. Recruitment of mRNA to ribosomes typically involves interaction of the $5^{\prime} \mathrm{m}^{7} \mathrm{GpppN}$ (cap) structure with eukaryotic cap-binding protein, also known as eukaryotic initiation factor (elF)4E. elF4E is part of the cap-initiation complex (also known as elF4F), which functions to bridge mRNA, the ribosome and the initiation machinery consisting of elFs and other proteins. elF4F contains two additional polypeptides: the scaffold protein, elF4G which binds elF4E, and elF4A, an ATP-dependent RNA helicase. elF4G also interacts with elF3, a complex factor that binds the $40 \mathrm{~S}$ ribosomal subunit, the poly(A)binding protein, which stimulates translation, and the MAP kinase-interacting kinases Mnk1 and Mnk2, which phosphorylate elF4E at serine 209 when associated with elF4G. ${ }^{15,16}$ Dephosphorylation of elF4E during cell stresses such as heat shock, nutrient deprivation, cell cycle arrest and some forms of viral infection correlates with impairment of cap-dependent translation. ${ }^{16,17}$ A slight decrease in elF4E phosphorylation has also been reported during global cerebral ischemia. ${ }^{8,11}$ Overall, the significance of elF4E phosphorylation remains uncertain as conflicting results have been reported concerning its role in translational regulation. ${ }^{11,18-20}$

Three related elF4E-binding proteins (4E-BP1, 2, 3) negatively regulate the formation of the elF4F complex and consequently can control cap-dependent mRNA translation. 4E-BP1 binds to elF4E and competitively inhibits its association with elF4G, preventing the formation of cap-initiation complexes and impairing cap-dependent mRNA translation. ${ }^{16}$ Hyperphosphorylation of 4E-BP by mammalian target of rapamycin (kinase) (mTOR) inhibits its binding activity and releases elF4E from sequestration. ${ }^{3}$ The phosphorylation status of 4E-BP1 is representative of the pathway and is affected by a variety of stimuli. Phosphorylation and inactivation of 4E-BP1 occurs in response to mitogenic stimuli such as hormones, growth factors, amino acids and other stimuli, and is mediated through the mTOR/PI3kinase/Akt-signaling pathway. ${ }^{3}$ Activation (hypophosphorylation) of 4E-BP1 occurs in cell culture during heat shock, viral infection, amino-acid starvation, hypoxia, and in animals during cerebral ischemia. $3,13,16,17,21,22$ 
An additional mechanism that is potentially important for regulating translation initiation during ischemia is the proteolysis of elF4 proteins, particularly elF4G. A significant decrease in elF4G during cerebral ischemia has been reported $^{9,11,13}$ and it has been proposed that elF4G degradation is a consequence of ischemia-induced calpain activation. ${ }^{11,23}$ In tissue culture cells, caspase-3-mediated cleavage of elF4G also occurs early during apoptosis and participates in the induction of apoptotic cell death. ${ }^{20,24}$ Protein synthesis can also be inhibited at the elongation step by phosphorylation of eukaryotic elongation factor 2 (eEF2) on Thr-56. eEF2 mediates ribosomal translocation and is inhibited by eEF2 kinase. $^{25-28}$ Muscle tissue subjected to ATP depletion shows increased eEF2 phosphorylation concomitant with protein synthesis inhibition. ${ }^{29}$

Significant downregulation of protein synthesis has been demonstrated in myocardial cell lines cultured under hypoxic conditions, as well as in ischemic perfusion models of rat heart or skeletal muscle. However, these studies have provided conflicting results with regard to mechanism of translation inhibition. ${ }^{6,14,30-33}$ While extrapolation from experiments performed with tissue culture cells can be instructive, they are often not predictive of the magnitude or importance of specific physiological responses in animal tissues and organs. Moreover, studies utilizing heart tissue perfusion are not often representative of responses in the nonperfused tissue. For example, some studies in different tissues report that ischemia inhibits cap-dependent translation through downregulation of the mTOR pathway and activation of 4E-BP1, ${ }^{30,32,33}$ while others report translation to be inhibited globally through inhibition of eEF2. ${ }^{14}$ We therefore sought to characterize the mechanisms of translational regulation that occur during acute myocardial ischemia in the rat heart by examining the alterations in translation factor abundance, activity (using specific phosphorylation events as surrogate markers) and the composition of the translation initiation complex.

\section{Results}

\section{Initiation factor levels and phosphorylation status during ischemia}

Using a rat acute ischemic model of myocardial function, we therefore first examined the abundance of translation factors and their phosphorylation status when indicative of activity. Cardiac ischemia was induced in adult rats by ligature of the left coronary artery. EKG tracings were recorded to monitor heart function 5-10 min before and following the ligature for all rats, ranging from 1 to $12 \mathrm{~h}$. Representative EKG tracings demonstrated that ischemia was apparent in animals at $10 \mathrm{~min}$, became quite pronounced at $1 \mathrm{~h}$ and severe by $6-12 \mathrm{~h}$ (data not shown). After induction of ischemia monitored by EKG recordings, animals were killed, the myocardium was rapidly removed, dissected into $L V$ and $R V$ sections and flash frozen. Control samples correspond to combined LV and RV of mock-treated animals.

Equal amounts of tissue were subjected to detergent lysis, resolved by SDS-PAGE and specific proteins were detected by immunoblot analysis using antibodies that specifically recognize the different translation factors or their phosphorylated forms. All immunoblots were quantified by densitometry, and results shown are typical of three independent experiments using three rats each. There was no change in the overall abundance of elF4A between control and ischemic heart tissues at any of the time points tested (Figure 1a). elF4A therefore was used as an appropriate control for protein loading throughout this study. There was no significant change in total levels of eEF2 or its phosphorylation at inhibiting site Thr-56 (Figure 1c). The levels of elF4E were unchanged during the period of ischemia up to $6 \mathrm{~h}$, but decreased $\sim 4$-fold by $12 \mathrm{~h}$ of severe ischemia in the obstructed LV only (Figure 1a, $P<0.05$ ). Phosphorylation of elF4E at serine 209 is associated with increased translation activity, and decreased phosphorylation with reduced translation. ${ }^{16}$ A significant reduction was observed in elF4E phosphorylation at serine 209 by $6 \mathrm{~h}$ ( $\sim 10$-fold), which became undetectable by $12 \mathrm{~h}$ of ischemia (Figure 1a, $P<0.05)$.

The elF4E-binding protein 4E-BP1, which blocks elF4E interaction with elF4G, was shifted to the hypophosphorylated (activated) form by 10 min of ischemia in both LV and RV

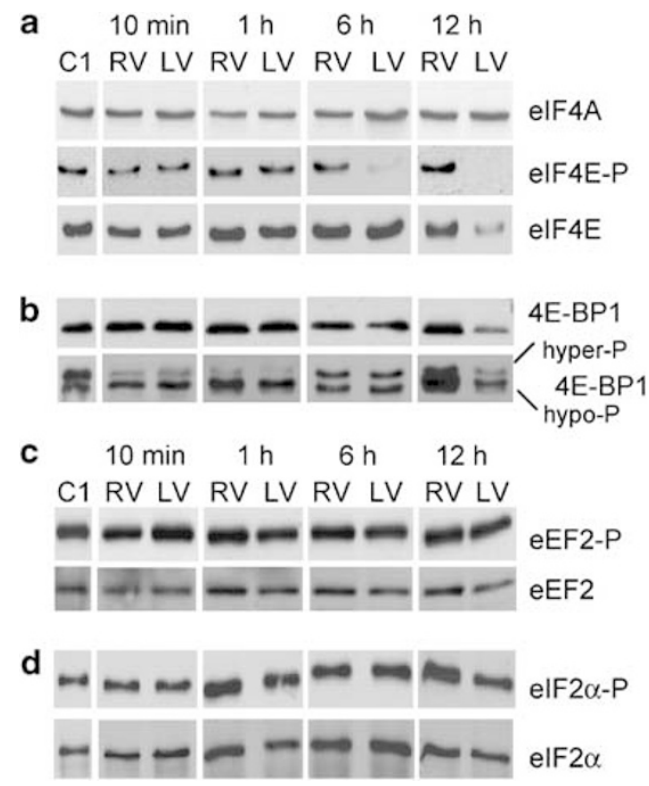

Figure 1 Effect of myocardial ischemia on abundance and phosphorylation of key translation initiation factors. Rats were subjected to left coronary artery ligature for the times shown, or underwent sham surgical procedures (control, C1), then LV and RV were excised and flash frozen. Following tissue homogenization, mild detergent lysates were prepared from the different samples, normalized for soluble protein content, resolved by SDS-PAGE and proteins identified by immunoblot analysis with specific antisera as shown. Representative immunoblots are shown of 2-3 rats and at least three independent tissue section extracts. (a) Immunoblot analysis of equal amounts $(50 \mu \mathrm{g})$ of elF4A, elF4E, serine-209 phosphorylated form of elF4E, resolved by SDS-15\% PAGE. (b) A low-resolution SDS-8\% PAGE analysis of total 4E-BP1 levels, high-resolution SDS-15\% PAGE of hyperphosphorylated and hypophosphorylated forms of 4E-BP1, using extracts prepared as described above. (c) Immunoblot analysis of Thr-56 phosphorylation of eEF2 and total eEF2 protein levels in protein lysates, prepared as above. (d) Immunoblot analysis of serine-53 phosphorylated elF2 $\alpha$ and total elF2 $\alpha$ protein levels in lysates, prepared as above. Data were quantified by densitometry of autoradiograms 
(Figure 1a and b), indicating that both sides of the heart initially sense and respond to the ischemic stress by activating 4E-BP1. At $1 \mathrm{~h}$ of ischemia, stronger activation (hypophosphorylation) of 4E-BP1 was evident in both the obstructed LV and in the control RV. Surprisingly, by $6 \mathrm{~h}$, as ischemia becomes quite severe, we consistently observed a profound reversal of the response of the mTOR/4E-BP1 pathway to ischemic stress. In both the LV and RV, 4E-BP1 underwent inactivation (hyperphosphorylation) consistent with its release of elF4E and formation of cap-initiation complexes. In addition, analysis of 4E-BP1 by low-resolution SDS-8\% PAGE (to avoid separation of the multiple phosphorylated species) demonstrated an overall decrease in 4E-BP1 levels only in the LV by $12 \mathrm{~h}$ of ischemia (Figure $1 \mathrm{~b}$ ). No significant change was found in total elF2 $\alpha$ protein or phosphorylation levels (Figure 1d). These data are consistent with previous reports that show no change in phosphorylation of elF $2 \alpha$ in cerebral ischemia. ${ }^{10,13,34}$ As the $12 \mathrm{~h}$ ischemic samples are similar to the $6 \mathrm{~h}$ time points, this time point has been omitted from the remaining studies to be presented.

\section{Alteration of elF4G levels during ischemia}

elF4G is thought to be the most limiting of translation initiation factors and has been reported to negatively control translation by its insolubilization in stress granules, by phosphorylation which may affect its activity, and by degradation during apoptosis. $^{20}$ The abundance of elF4G was examined by SDS-PAGE and immunoblot analysis of equal amounts of tissue lysates. Of note, elF4G migrates in high-resolution gels as several related polypeptides representing both differentially phosphorylated forms and up to five isoforms ${ }^{35}$ (only the major $a$ and $b$ isoforms were resolved here). There was no change in elF4G abundance during the first $10 \mathrm{~min}$ of acute ischemia (Figure 2a). However, a $60-70 \%$ decrease in the level of elF4G was found in the ischemic LV compared to the control RV at $1 \mathrm{~h}$, comprising in particular the major b-isoform of the protein. The loss of elF4G specifically in the LV was striking at $6 \mathrm{~h}$ of acute ischemia and nearly complete, representing all of the electrophoretic species (Figure 2a). There was no change in the abundance of elF4A, serving as an internal control. Studies next determined whether the reduced abundance of elF4G was a result of entrance into insoluble complexes or degradation during acute ischemia. The insoluble protein fraction remaining after tissue lysis was solubilized by extraction with harsh detergent and mechanical dissolution, shown previously to release elF4G from insoluble complexes. ${ }^{36}$ The solubilized protein fraction was resolved by SDS-PAGE and elF4G was detected by immunoblot analysis. The amount of elF4G in insoluble complexes was small, as the entire fraction was required for detection, and there was no significant change in the abundance of elF4G in the insoluble protein fraction during acute ischemia in either the LV or RV (Figure 2b). Thus, a small but stable insoluble fraction of elF4G exists within cardiomyocytes, but it does not change under ischemic stress. Given the significant loss of elF4G, we examined the accumulation of potential elF4G degradation products (Figure $2 \mathrm{c}$ ) by probing high-resolution SDS-PAGE gels with a multivalent antibody
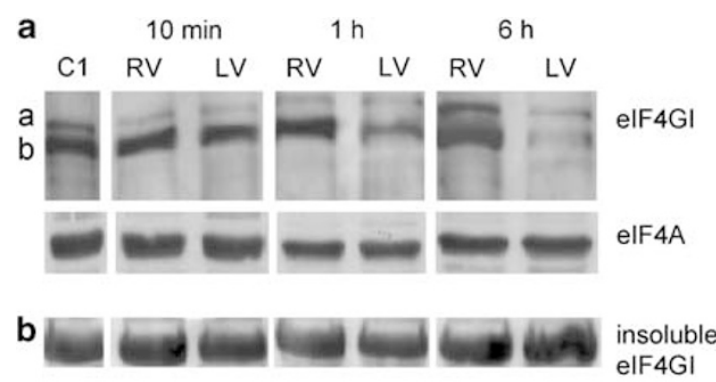

c elF4GI fragments in LV

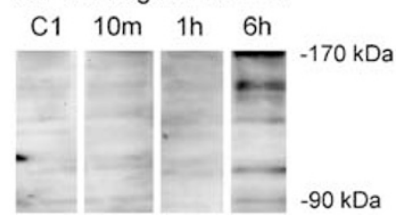

Figure 2 Effect of myocardial ischemia on translation initiation factor elF4GI abundance and formation of insoluble complexes. (a) Equal amounts $(50 \mu \mathrm{g})$ of myocardial soluble protein lysates from control (C1) sham-operated, RV and obstructed LV samples were resolved by SDS-15\% PAGE. Immunoblot analysis was performed using a human elF4GI antibody that crossreacts with the rat homolog. (b) The insoluble protein fraction of myocardial lysates was recovered and solubilized, resolved by SDS-PAGE and elF4GI detected by immunoblot analysis. Data are representative of three independent experiments involving at least two rats each. Data were quantified by densitometry of autoradiograms. (c) Lysates prepared for (a) above were resolved in higher resolution SDS-PAGE and detected by immunoblot using a polyclonal antibody to multiple regions of elF4G

to elF4G. While there was clear evidence for multiple elF4G-related protein fragments in the LV of $6 \mathrm{~h}$ ischemic myocardium, only a very low level of elF4G-related protein fragments were detectable in the control myocardium, as well as in the $10 \mathrm{~min}$ and $1 \mathrm{~h}$ ischemic LV. These studies suggest that the loss of elF4G at late times of ischemia $6 \mathrm{~h}$ and later) might occur through its increased degradation, but this cannot account for loss of elF4G from the soluble translationally active pool at $10 \mathrm{~min}$ and $1 \mathrm{~h}$. Studies presented later indicate that the decreased levels of elF4G at $1 \mathrm{~h}$ of ischemia results from its relocalization into stress granule-like macromolecular complexes.

\section{Analysis of elF4E association with 4E-BP1 and elF4G}

Activation (dephosphorylation) of 4E-BP1 and its binding to elF4E at the same site occupied by elF4G, competitively displaces elF4E from elF4G and disrupts cap-dependent translation initiation complexes, downregulating cap-dependent mRNA translation. ${ }^{16}$ We therefore investigated whether the dephosphorylated form of 4E-BP1 that accumulates during acute myocardial ischemia sequesters elF4E from cap-initiation complexes. The fraction of elF4E associated with 4E-BP1 and elF4G was examined by purification of complexes from NP-40 detergent tissue lysates using 7-methyl GTP-Sepharose beads and proteins were detected by immunoblot analysis. Studies compared elF4E interaction with elF4G and 4E-BP1 from control (nonischemic) heart tissue to LV and RV following LV coronary ligature, as 
$\mathrm{m}^{7}$ GTP-cap-chromatography

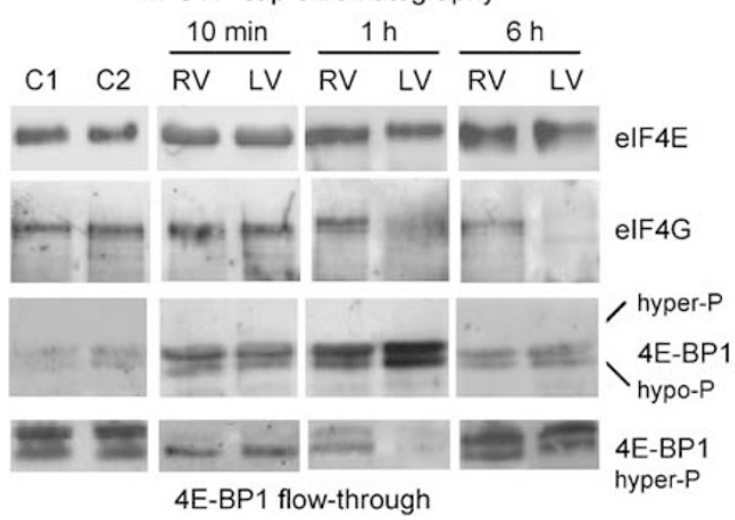

Figure 3 Analysis of elF4E interaction with 4E-BP1 during myocardial ischemia. Equal amounts of soluble, detergent-extracted myocardial protein lysates from sham-operated control rats $(\mathrm{C} 1, \mathrm{C} 2)$ and ischemic rat hearts were subjected to $m^{7}$ GTP-Sepharose cap analog chromatography, recovered by elution with GTP and resolved by SDS-15\% PAGE followed by immunoblot analysis with antisera to elF4E or 4E-BP1. The unretained flow-through fraction from cap-chromatography was recovered prior to elF4E elution, equal amounts were resolved by SDS-PAGE and 4E-BP1 was detected by immunoblot analysis. Data are representative of three independent experiments involving at least two rats each

described above. There was only a very low level of interaction between 4E-BP1 and elF4E in nonischemic control heart tissues and most 4E-BP1 appeared in the flow-through fraction (Figure 3). Accordingly, elF4E was predominantly associated with elF4G in these tissues. In contrast, there was a modest increase in association of 4E-BP1 with elF4E at $10 \mathrm{~min}$ of ischemia in both the $\mathrm{LV}$ and $\mathrm{RV}$, and a reciprocal modest loss of 4E-BP1 in the nonretained flow-through fraction. A slight decrease in elF4E association with elF4G was also detected. By $1 \mathrm{~h}$ of ischemia, the amount of 4E-BP1 bound to elF4E increased strongly in the obstructed LV, and reciprocally decreased in association with elF4G, indicating a significant gain in the ability to sequester elF4E from cap-initiation translation complexes. Recovery of 4E-BP1 in the flow-through fraction decreased accordingly. Although 4E-BP1/elF4E association persists throughout ischemia, it decreased significantly by $6 \mathrm{~h}$ and appears in the flow-through fraction unbound to elF4E (Figure 3 ). The recoverable fraction of full-length elF4G associated with elF4E also strongly decreased.

We also performed a reciprocal set of studies to characterize the state of elF4E interaction with recovered elF4G as an indication of cap-dependent mRNA translation (Figure 4). Equal amounts of tissue lysates were subjected to immunoprecipitation with anti-eIF4G antibody, SDS-PAGE and immunoblot analysis to determine the association of elF4E with isolated elF4G. elF4G that was immunoprecipitated was normalized in Figure $4 \mathrm{a}$ and $\mathrm{b}$ and detected by immunoblot analysis using low-resolution SDS-PAGE gels (to avoid separation of isoforms). In panel $c$ this was not possible due to degradation and sequestrate of elF4G at this late $(6 \mathrm{~h})$ time point. Surprisingly, there was no significant change in association between eIF4G and elF4E in either the RV or LV samples at $10 \mathrm{~min}$ of acute ischemia, compared to control heart (C2) from a mock-treated animal (Figure 4a). Thus,

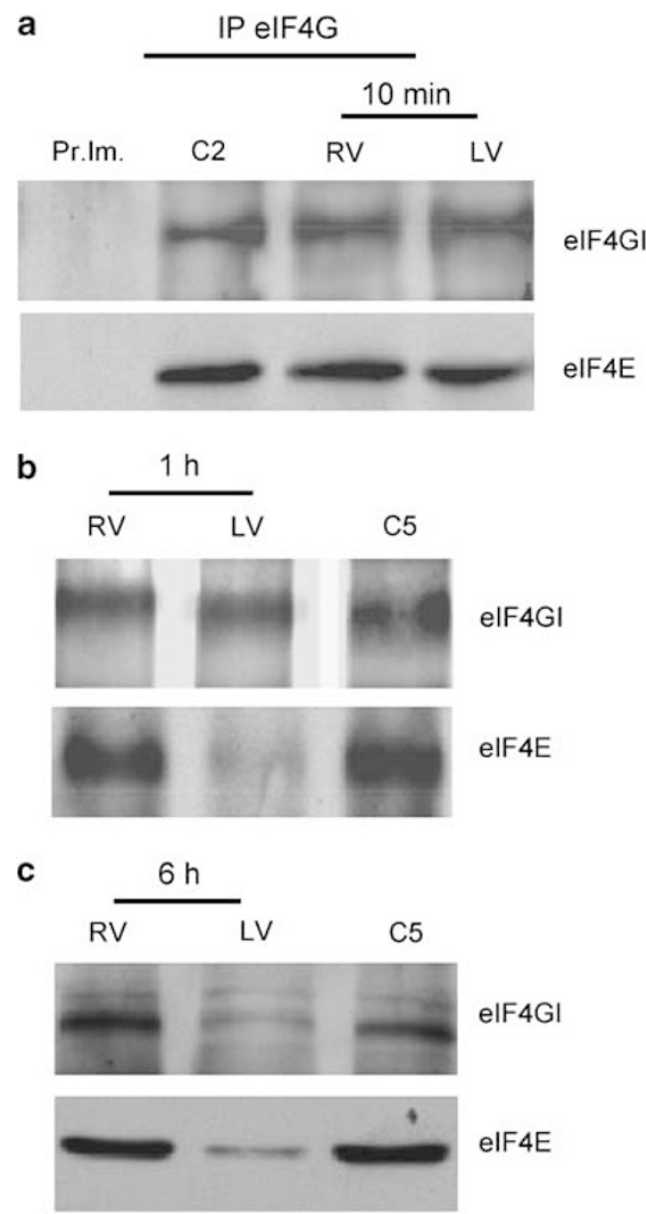

Figure 4 Analysis of elF4E interaction with elF4G during myocardial ischemia. Equal amounts of soluble, detergent-extracted myocardial protein lysates from sham-operated control rats (C2) and ischemic rat hearts were subjected to immunoprecipitation with either preimmune (preim.) rat sera or anti-human elF4GI antibodies. Immunoprecipitates from (a) $10 \mathrm{~min}$ and (b) $1 \mathrm{~h}$ ischemic hearts were resolved by SDS-15\% PAGE. elF4GI and elF4E were detected by immunoblot analysis. Data are representative of three independent experiments involving at least two rats each. Data were quantified by densitometry of autoradiograms

despite a detectable association between 4E-BP1 and elF4E at this time (Figure 3), the actual size of the pool of 4E-BP1 relative to elF4G is insufficient to competitively displace elF4E from elF4G. However, by $1 \mathrm{~h}$ of ischemia, there was a specific and largely complete reduction in elF4E bound to elF4G, which was observed only in the ischemic $L V$, with no alteration in the RV (Figure 4b). The interaction of elF4E with elF4G at the later time of acute ischemia (6h, Figure $4 \mathrm{c})$ failed to detect significant levels of elF4G and associated elF4E because elF4G was degraded and/or sequestered. Thus, the strong activation of 4E-BP1 and its binding to elF4E immediately following ischemia is insufficient to deplete cap-initiation complexes, but with reduced abundance of elF4G at $1 \mathrm{~h}$ of ischemia, inhibition of cap-initiation complex formation was observed. These data also suggest that only a fraction of elF4E must be in a complex with elF4G, which would explain the ability of 4E-BP1 to initially bind elF4E without disrupting cap-initiation complexes. 
Caspase-3 activation, elF4G proteolysis and cardiomyocyte death are temporally associated during prolonged acute ischemia

Prolonged ischemia promotes obvious tissue destruction and cell death in many organs. ${ }^{37}$ Moreover, activation of caspase3 , a key executioner caspase, occurs in neurons during global acute brain ischemia, ${ }^{38,39}$ and during induction of apoptosis in a variety of tissues and cell types. ${ }^{20,24,40}$ Activation of caspase-3 is therefore a reliable indicator of induction of apoptotic cell death. In addition, studies in tissue culture report that caspase-3 cleaves elF4G and possibly other factors as a means to enact translation inhibition leading to apoptotic cell death. ${ }^{20}$ Studies also indicate that products of the elF4G proteolysis function in promoting the proapoptotic program as well. ${ }^{41-43}$ We therefore determined whether caspase-3 is activated during the course of acute myocardial ischemia in a manner temporally consistent with elF4G degradation and 4E-BP1 sequestration of elF4E. Heart tissue lysates were prepared, resolved by SDS-PAGE and proteins detected by immunoblot analysis for both full-length caspase- 3 and its activated cleavage product (Figure 5). Control studies showed that there was no significant alteration in total caspase-3 levels throughout the period of acute ischemia (Figure 5, top panel). However, a high level of caspase-3 activation was apparent by $6 \mathrm{~h}$ of acute ischemia, and only in the obstructed LV, shown by a significant accumulation of the caspase-3 cleavage product (Figure 5, lower panel). A slight decrease in caspase-3 coincident with accumulation of its cleavage product is further evidence for its activation. These data indicate that only cardiomyocytes in the obstructed LV initiate apoptotic death by $6 \mathrm{~h}$ of acute ischemia. Importantly, there was no evidence for caspase-3 activation at $1 \mathrm{~h}$ of ischemia, at a time when elF4G levels decrease by $60-70 \%$ (Figure 2 ) and elF4E is sequestered by 4E-BP1 (Figure 3). To investigate the extent of apoptosis in the acute ischemic heart, $5 \mu \mathrm{M}$ cryosections of unstressed control, RV and obstructed LV tissues were fixed and stained for immunohistochemical identification of activated caspase-3. By $12 \mathrm{~h}$ of acute ischemia $>50 \%$ of LV cardiomyocytes were in apoptosis, compared to $<10 \%$ of $\mathrm{RV}$ and $<5 \%$ of control heart cardiomyocytes (data not shown). Collectively, these data indicate that the strong loss of elF4G and elF4E at $12 \mathrm{~h}$ of ischemia, and the more modest reduction in 4E-BP1 temporally occurs with cardiomyocyte cell death.

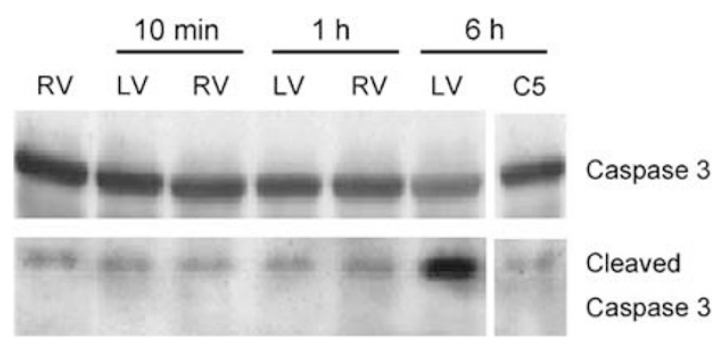

Figure 5 Activation of caspase-3 during myocardial ischemia. Equal amounts $(30 \mu \mathrm{g})$ of soluble protein extracts from control (C5) and ischemic myocardium were resolved by SDS-15\% PAGE. Immunoblot analysis was carried out using antibodies that detect either full-length caspase-3 or the activated cleaved protein fragment of caspase-3. Data represent typical results from three independent trials of two rats each

\section{Cardiomyocyte elF4G relocalization during ischemia}

Induction of certain physiological stresses including heat shock, exposure to chemotoxins and hypoxia are associated with the relocalization of eIF4G into NP-40 detergent-resistant macromolecular complexes, including stress granules, which contain the protein TIAR. ${ }^{44}$ We therefore investigated whether a similar relocalization of elF4G occurs during progressive ischemia in the myocardium and could account for a nonproteolytic decrease in elF4G abundance, particularly at $1 \mathrm{~h}$ when cap-initiation complex assembly is disrupted and there is no evidence for caspase-3 activation. Myocardium from both ischemic and mock-treated rat hearts were dissected into LV and RV then frozen in OCT for cryosectioning. Samples were sectioned to $5 \mu \mathrm{M}$, fixed with acetone and stained with an FITC-conjugated antibody against elF4G, a Cy5-conjugated antibody to TIAR and with propidium iodide to stain the nuclei (Figure 6). In normal (nonstressed) tissue sections, elF4G was abundant, found diffusely in the cytoplasm, in striated bands and at interfacing cellular junctions, in addition to some perinuclear and nuclear distribution (Figure 6a). There was little colocalization with TIAR protein in control cardiomyocytes. However, within $1 \mathrm{~h}$ of acute ischemia in the LV, a significant relocalization of elF4G was apparent (Figure 6b), demonstrating strong reduction in levels from all sites and significant accumulation in large cytoplasmic bodies. Much of the relocalized elF4G was in association with TIAR protein, which relocalized to the same large bodies. Thus, the reduction in elF4G at $1 \mathrm{~h}$ of ischemia, the lack of caspase- 3 activation at this time and the movement of both eIF4G and TIAR to colocalized bodies, suggests that a
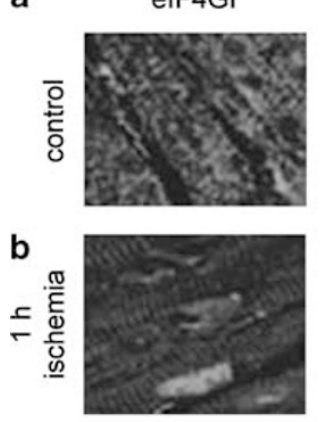

C

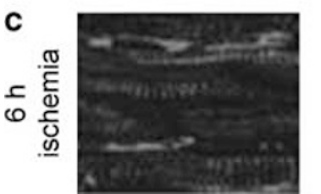

TIAR
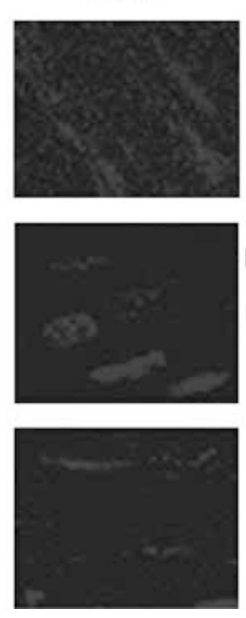

Merge
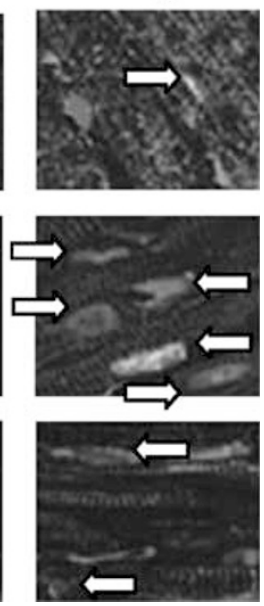

Figure 6 Relocalization, stress granule macromolecular complex formation and loss of elF4G during acute myocardial ischemia. Myocardium from both nonischemic and ischemic rat hearts were subjected to LV ligature, dissected into LV and RV, and frozen in OCT for cryosectioning. Samples were cut to $5 \mu \mathrm{M}$ sections, fixed in acetone and stained with antibody to eIF4GI (FITC conjugated, green), stress granule protein TIAR (Cy5-conjugated, blue) then the nuclei were stained with propidium iodide ( $\mathrm{PI}$, red). Individual and merged images are shown. (a) Control LV; (b) $1 \mathrm{~h}$ ischemic LV and (c) $6 \mathrm{~h}$ ischemic LV. In normal cardiomyocytes, elF4G is found in striated bands interfacing cellular junctions. Arrows indicate colocalization of TIAR and elF4GI. All photographic images were obtained at identical $\times 63$ magnification. Representative fields are shown 
at $1 \mathrm{~h}$ of ischemia more than half of elF4G associates with TIAR macromolecular complexes. By $6 \mathrm{~h}$ of ischemia, overall loss of elF4G was apparent in the LV specimens, with small amounts of remaining eIF4G in association with TIAR (arrows in Figure 6c). It is also important to note that breakdown of nuclei was evident by $6 \mathrm{~h}$, consistent with initiation of cardiomyocyte apoptosis (Figure 6c) and activation of caspase-3. Only a slight relocalization of elF4G was apparent in the RV at all time points (data not shown).

\section{Discussion}

In this study, we investigated the mechanisms underlying suppression of protein synthesis during myocardial ischemia in an in vivo rat model. It has been previously reported that protein synthesis is strongly inhibited following myocardial ischemia. ${ }^{6}$ Both the initiation and elongation steps of protein synthesis are high-energy processes, and both are subject to several different forms of regulation. During myocardial ischemia we found no significant change in the phosphorylation of elF2 $\alpha$, excluding elF2-GTP recycling as a targeted form of ischemic regulation of translation in the myocardium. While initially surprising given reports of elF $2 \alpha$ phosphorylation in translational control of tissue culture cell hypoxia, ${ }^{45}$ these results are consistent with previous reports in cerebral ischemia. ${ }^{9-11,13}$ It is hypothesized that during ischemia, depletion of ATP is so severe that it may inactivate mechanisms that promote elF $2 \alpha$ phosphorylation. ${ }^{11}$ It is widely accepted that elF $2 \alpha$ phosphorylation plays a significant role in translation inhibition during reperfusion, but this mechanism cannot account for suppression of protein synthesis during cerebral ischemia ${ }^{9-11,13}$ or myocardial ischemia (as shown here).

As for the role of translation elongation in myocardial ischemia, a slight increase in eEF2 phosphorylation in the LV was observed at $10 \mathrm{~min}$, which then returned to control levels for the duration of ischemia. These data are in contrast to the results of Horman et al. ${ }^{14}$ who reported a significant increase in eEF2 phosphorylation after 10 min of myocardial ischemia. It is possible that this difference can be accounted for by differences in the experimental system, as their studies utilized a heart perfusion method that maintains blood flow during ischemia. Our results, which recapitulate LV obstruction, are similar to those found in cerebral ischemia, where only a slight increase or no change in eEF2 phosphorylation was found. ${ }^{10,12}$ The slight elevation we observed in eEF2 phosphorylation is unlikely to play a role in inhibition of translation early during myocardial ischemia, as a large increase in eEF2 phosphorylation is required to deplete the pool of this factor. ${ }^{22}$ It has been postulated that if regulation of translation elongation is involved in protein synthesis inhibition during ischemia, it would most likely represent an ischemia-induced overall energy failure rather than a targeted alteration of eEF2 phosphorylation. ${ }^{12}$

Several forms of regulation at the level of translation initiation were observed in myocardial ischemia. A large shift of 4E-BP1 to the dephosphorylated (activated) form was observed within 10 min of ischemia, in both the ischemic LV as well as the RV. It is not surprising that LV obstruction has a global stress effect on the heart. However, it is surprising that following ischemia, both the RV and LV reverse 4E-BP1 activation, shifting back to the inactive hyperphosphorylated form by $6 \mathrm{~h}$ (Figure 1b). Thus, the heart appears to respond to $L V$ ischemia initially by global activation of 4E-BP1, which is ultimately reversed in the $\mathrm{RV}$, probably to stimulate protein synthesis, and compensate for failing cardiomyocyte function in the LV.

The most surprising aspect of this work is the discovery of a decrease in elF4G abundance at $1 \mathrm{~h}$ of ischemia, which reduces competition for elF4E and enables 4E-BP1 sequestration of elF4E and disruption of cap-initiation complexes. Decreased abundance of elF4G at $1 \mathrm{~h}$ appears to result from relocalization with TIAR protein to large bodies, not from degradation. However, the strong decrease in elF4G observed in the stressed LV by $6 \mathrm{~h}$ of ischemia is a result of proteolytic degradation, as found during cerebral ischemia. ${ }^{9,11,13,23}$ Although calpain I activation has been suggested as a possible mechanism for elF4G degradation during cerebral ischemia, ${ }^{23}$ our results are consistent with caspase-3 activation which mediates elF4G degradation during apoptosis in tissue culture cells. ${ }^{40}$ Caspase- 3 was not activated at $1 \mathrm{~h}$ of ischemia, but was strongly activated in the LV by $6 \mathrm{~h}$ of ischemia, which correlates with the kinetics of elF4G degradation. However, it is possible that there is some crosstalk between calpain I and caspase-3 systems in elF4G degradation, as has been previously suggested during neuronal apoptosis. ${ }^{38}$ We did not detect calpain I activity during this time period (data not shown). Nevertheless, elF4E is not thought to be degraded by caspase- 3 but may be a substrate for calpain I, ${ }^{20}$ and elF4E degradation did not occur later in ischemia following caspase- 3 activation. The decrease in elF4G levels accounts for the reduction of cap-initiation complexes observed during prolonged ischemia despite increased inactivation of 4E-BP1. In addition to the strong decrease in elF4G by degradation, we observed a significant and specific decrease in elF4E and 4E-BP1 during this same period. It is significant to note that all of the decreased factors occurred in the ischemic LV and not in the RV. This is consistent with earlier research demonstrating that cell death in the myocardium is limited to the tissue undergoing ischemic stress and is not a global effect. ${ }^{37}$

The relocalization of elF4G into TIAR complexes during myocardial ischemia, as determined by immunofluorescence staining of frozen sections, is temporally consistent with initial loss of elF4G from the free pool of factor and disruption of cap-initiation complexes by $4 \mathrm{E}-\mathrm{BP} 1$. The degradation of elF4G and elF4E in the ischemic heart and the cessation of protein synthesis are linked to the induction of apoptosis in tissue culture systems. In the ischemic rat myocardium, the vast majority of translationally available elF4G also undergoes proteolysis. Given that there are differences between human and rat elF4G sequences, it is also not possible to predict whether the elF4G fragments detected in ischemic rat LV are representative of those shown to help orchestrate apoptotic destruction of highly stressed human tissue culture cells (unpublished studies). ${ }^{20}$ In summary, we have shown that acute ischemia disrupts cap-dependent mRNA translation through a mechanism involving relocalization of a fraction of elF4G 
into TIAR protein complexes, which initiates 4E-BP1 sequestration of elF4E.

\section{Materials and Methods}

\section{Materials}

\section{Antibodies}

Rabbit polyclonal antiserum specific to the N-terminal region of human elF4GI was provided by RE Lloyd (Baylor College of Medicine, Houston, TX, USA), antibodies that recognize rat elF4G were provided by $\mathrm{N}$ Sonenberg (Mchill University Montreal, Canada), and mouse monoclonal anti-elF4A antibody was provided by W. Merrick (Case Western Reserve University, Cleveland, $\mathrm{OH}, \mathrm{USA}$ ). Other antisera were from commercial sources and include rabbit polyclonal antibodies against elF4E, elF4E-P (Ser209), 4E-BP1, eEF2, eEF2-P (Thr 56), caspase-3 from Cell Signaling Technology, rabbit polyclonal anti-elF2 $\alpha \mathrm{P}$ (Ser51) antibody (Biosource), rabbit polyclonal anti-elF2 $\alpha$ antibody, goat polyclonal anti-TIAR antibody from Santa Cruz Biotechnology, and horseradish peroxidase-conjugated donkey anti-rabbit or sheep antimouse secondary antibodies (Amersham). The enhanced chemiluminescence system (Amersham) was used for detection.

\section{Animals}

All experiments were conducted in accordance with a protocol approved by Aventis Animal Care and Use Committee and conform to the $\mathrm{NIH}$ Guidelines for the Use and Care of Laboratory Animals. Sprague-Dawley rats (24 males) weighing $260-444 \mathrm{~g}$ were obtained from Charles River (Charles River, 59, rue de la Paix 76410 saint Aubin Les Elbeuf, France). They were kept in animal quarters according to good animal care practices for at least 1 week preceding their utilization. Throughout this period they were housed 2-3 animals per cage, had free access to food (M20, Ets L. Piètrement, Ste Colombe, 77650 Longueville, France) and appropriately filtered drinking water. The animal house was maintained on a 12-h light/ dark cycle with an ambient temperature of $20-24^{\circ} \mathrm{C}$ and humidity set at $35-75 \%$.

\section{Electrophysiological measurements before and after myocardial ischemia}

Rats were anesthetized with an intraperitoneal (i.p.) injection $(1 \mathrm{ml} / \mathrm{kg}$ ) of a mixture of xylazine $6 \mathrm{mg} / \mathrm{kg}$ and ketamine $70 \mathrm{mg} / \mathrm{kg}$. The internal temperature of animals was maintained constant $\left(36-38^{\circ} \mathrm{C}\right)$ with a homeothermic blanket (Homeothermic blanket system, HarvardApparatus, France). EKG parameters were measured via electrodes placed on limbs to record the DII standard derivation and filtered with low and high cutoff ( 0.1 and $100 \mathrm{~Hz}$, respectively). Records were made at the speed of $100 \mathrm{~mm} / \mathrm{s}$. Parameters were displayed on a polygraph (Gould).

\section{Rat ischemia model}

Anesthesia was induced with a mixture of ketamine $(70 \mathrm{mg} / \mathrm{kg})$ and xylazine $(6 \mathrm{mg} / \mathrm{kg})$ under the volume of $1 \mathrm{ml} / \mathrm{kg}$ given intraperitoneally. Rats were maintained under artificial ventilation ( $1 \mathrm{ml} / 100 \mathrm{~g}, 70$ inspiration/ min) delivered via a respirator (Harvard Apparatus, France) throughout the experimental procedure. The internal temperature of animals was maintained constant $\left(36-38^{\circ} \mathrm{C}\right)$. Animals were placed in dorsal decubitussupine position and a left thoracotomy was performed at the 5 th intercostal space by using aseptic surgical conditions. An intercostal retractor was positioned to maintain free access to the heart, the apex of which was partially positioned outside the thorax. Coronary ligation of the left ventricle coronary artery was performed $2 \mathrm{~mm}$ from its origin (6/0 silk Ethibond thread). The heart was repositioned inside the thorax that was subsequently closed, except for the $10 \mathrm{~min}$ and $1 \mathrm{~h}$ time points, by stitching the wound in a two layer procedure (Mersutures (4/0) and Vicryl 4/0 (Ethicone)). The air in the pneumothorax was then gently reduced by external compression. After breathing recovery, the animals were replaced individually in a box until the end of the experiment. The control animals were treated in an identical fashion including administration of anesthesia but did not undergo ligature tie off.

\section{Sample harvesting after ischemia}

Anesthesia was induced as described, and EKG parameters were recorded as described above. With termination of the experiment the heart was rapidly excised for macroscopic observation and momentarily placed in ice-cold saline solution to remove blood and preserve biochemical events. For biochemical evaluations, hearts were rapidly dissected into two parts. The left ischemic myocardium without the septum (identified as LV) was separated from the normal right ventricle myocardium (identified as RV). Each sample was then rapidly frozen in liquid nitrogen and stored at $-80^{\circ} \mathrm{C}$ until analysis. Surgical removal, washing, dissection, and flash freezing were carried out within 15 min to preserve tissue and biochemical integrity. Two animals from the control group and one from each time point were used for cryosections. Each heart was then dissected into four parts. The left ischemic myocardium without the septum identified as LV was separated and split in two samples along the anterio-posterior axis. One sample was preserved in OCT and frozen in a liquid nitrogen cooled solution of isopentane, then placed in liquid nitrogen and stored at $-80^{\circ} \mathrm{C}$ until analysis. The other sample was placed in a PBS/formol 3.7\% solution and fixed for $6 \mathrm{~h}$, rinsed twice in $50 \%$ ethanol and stored in $70 \%$ ethanol until histological analysis. The RV underwent the same preparation.

\section{Extract preparation}

Frozen ventricles were homogenized in $5 \times \mathrm{wt} / \mathrm{vol}$ of lysis buffer $(0.5 \%$. NP-40, $50 \mathrm{mM}$ Hepes, pH 7.5, $50 \mathrm{mM} \mathrm{KCl}, 50 \mathrm{mM} \mathrm{NaF}, 1 \mathrm{mM} \mathrm{Na}$ pyrophosphate, $1 \mathrm{mM}$ EDTA, $25 \mathrm{mM} \beta$-glycerolphosphate, $2 \mathrm{mM} \mathrm{Na}_{3} \mathrm{VO}_{4}$, $0.1 \mu \mathrm{M}$ okadaic acid, $1 \mathrm{mM}$ DTT, and one tablet of Complete Miniprotease inhibitor cocktail (Roche) per $10 \mathrm{ml}$ ) on ice using a Tekmar tissumizer (two times $30 \mathrm{~s}$ pulses) followed by centrifugation twice at $4{ }^{\circ} \mathrm{C}$ for $10 \mathrm{~min}$ at $11000 \times g$ to remove insoluble material. The supernatant was then collected and snap frozen in aliquots stored at $-80^{\circ} \mathrm{C}$. The insoluble pellet fraction of the NP-40 lysate was dissolved using ice-cold 1\% SDS lysis buffer ( $1 \%$ SDS, $50 \mathrm{mM}$ Tris- $\mathrm{HCl}, \mathrm{pH} 7.4,5 \mathrm{mM}$ EDTA, $10 \mathrm{mM}$ DTT, $15 \mathrm{U} / \mathrm{ml}$ DNAsel, and one tablet of Complete Miniprotease inhibitor per $10 \mathrm{ml}$ ) mixed by vortex five times with short $10 \mathrm{~s}$ pulses to solubilize protein. Samples were centrifuged at $4^{\circ} \mathrm{C}$ for $10 \mathrm{~min}$ at $11000 \times g$ and the supernatant and insoluble fraction were collected and stored in frozen aliquots at $-80^{\circ} \mathrm{C}$.

\section{Western blot analysis}

To determine the total levels and phosphorylation status of elF4G, elF4A, elF4E, elF2 $\alpha$, 4E-BP1, eEF2, as well as caspase-3 activity, equal amounts of protein from sham control and ischemic NP-40 tissue lysates were resolved by SDS-PAGE and analyzed by protein immunoblotting. The phosphorylation status of 4E-BP1 was determined by SDS-15\% PAGE, whereas $8 \%$ gels were used to determine total $4 \mathrm{E}-\mathrm{BP} 1$ levels. The 
phosphorylation status of elF4E, eEF2, and elF2 $\alpha$ were determined by immunoblotting membrane first with phosphospecific antibody, then stripping the membranes using Restore Western blot stripping buffer (Pierce), followed by reprobing the membranes with nonphosphospecific antibodies. Total elF4G levels were determined in both the soluble $(0.5 \%$ NP-40) and insoluble (1\% SDS) lysates by resolving equal amounts of protein by SDS-10\% PAGE and immunoblotting with an antibody raised against the $\mathrm{N}$-terminal region of elF4GI. Caspase-3 activity was determined by resolving samples on SDS-15\% PAGE and immunoblotting with a caspase- 3 antibody that recognizes both the cleaved (active) and uncleaved (inactive) forms of caspase-3. Three animals from each condition were analyzed in duplicate.

\section{elF4G immunoprecipitation and immunoblot analysis}

Equal amounts of protein from NP-40 tissue lysates were precleared with $0.75 \mathrm{ml}$ washed and pelleted Pansorbin Cells (Calbiochem) for $1 \mathrm{~h}$ at $4^{\circ} \mathrm{C}$. The supernatant was then incubated with $10 \mu$ rabbit polyclonal serum against the $\mathrm{N}$-terminal region of elF4Gl overnight at $4^{\circ} \mathrm{C}$. Protein A agarose was added and incubation was continued for $1 \mathrm{~h}$ at $4^{\circ} \mathrm{C}$ before precipitates were washed $4 \times$ with $1 \mathrm{ml} \mathrm{NP}-40$ lysis buffer, boiled in SDS-sample buffer and analyzed by SDS-PAGE and immunoblotting.

\section{Analysis of elF4E and 4E-BP1 interaction}

Equal amounts of protein from NP-40 tissue lysates were incubated with 7-methyl GTP-Sepharose 4B (30 $\mu$ l of settled bed volume) overnight at $4^{\circ} \mathrm{C}$. Pelleted beads were washed $4 \times$ with $1 \mathrm{ml} \mathrm{NP}-40$ lysis buffer, and resuspended in $0.6 \mathrm{ml}$ of NP-40 lysis buffer with $1 \mathrm{mM} \mathrm{GTP}$ for $1 \mathrm{~h}$ at $4^{\circ} \mathrm{C}$. Following a final $4 \times$ wash with $0.75 \mathrm{ml}$ of NP-40 lysis buffer, the beads were suspended in sample buffer and boiled, and the bound proteins were analyzed by SDS-PAGE and immunoblotting. 7-methyl GTP-Sepharose $4 \mathrm{~B}$ was obtained from Amersham Pharmacia Biotech.

\section{Confocal immunofluorescence microscopy of triple-labeled sections}

Tissue samples from OCT embedded RV and LV stored at $-80^{\circ} \mathrm{C}$ were cut to a thickness of $5 \mu \mathrm{M}$, fixed for 10 min with ice-cold acetone, then washed $3 \times$ with PBS. Tissue sections were permeabilized using $0.1 \%$ Triton X-100 in PBS for $10 \mathrm{~min}$ at room temperature, samples were blocked using $5 \%$ normal donkey serum, $0.1 \%$ Triton $X-100$, and $1 \mathrm{mg} / \mathrm{ml}$ RNaseA in PBS for $1 \mathrm{~h}$ at room temperature. Sections were then incubated overnight with primary antibody diluted in blocking solution (without RNaseA): rabbit polyclonal anti-elF4GI (1:100) and goat polyclonal anti-TIAR $(1: 100)$. Sections were washed with PBS and then incubated with donkey polyclonal anti-rabbit FITC (Jackson Immunoresearch), and donkey anti-goat Cy5 (AbCam) fluorescent secondary antibodies for $1 \mathrm{~h}$ at room temperature. After washing with PBS, sections were mounted using Vectashield-mounting medium for fluorescence with propidium iodide (Vector Laboratories). Slides were examined using a Zeiss Axiophot confocal microscope at $\times 63$ magnification.

\section{Statistical analysis}

Data were analyzed using the Student's unpaired $t$-test. All reported values represent means \pm S.D. of $10 \%$, with significance set at $P<0.05$.

\section{Acknowledgements}

This work was supported in part by grants from the Department of Defense and Aventis-Centillion, SAS, to RJ Schneider. We thank members of the Schneider lab for their critique of this study and helpful discussions. We also thank Nahum Sonenberg (McGill University) and Richard Lloyd (Baylor College of Medicine) for antibodies to elF4G, and W Merrick (Case Western Reserve University, Cleveland, $\mathrm{OH}, \mathrm{USA}$ ) for antibodies to elF4A.

\section{References}

1. Buttgereit $F$ and Brand MD (1995) A hierarchy of ATP-consuming processes in mammalian cells. Biochem. J. 312: 163-167

2. Schneider RJ (2000) Translational control during heat shock. In Translational Regulation, Hershey JWB, Mathews MB, Sonenberg N (eds) (Cold Spring Harbor, NY: Cold Spring Harbor Laboratory Press) pp. 581-594

3. Hay N and Sonenberg N (2004) Upstream and downstream of mTOR. Genes Dev. 18: 1926-1945

4. Proud CG (2004) The multifaceted role of mTOR in cellular stress responses. DNA Repair (Amsterdam) 3: 927-934

5. Mathews MB (1996) Interactions between viruses and the cellular machinery for protein synthesis. In Translational Control, Hershey JWB, Mathews MB, Sonenberg N (eds) (Cold Spring Harbor, New York: Cold Spring Harbor Press) pp. 505-548

6. Jefferson LS, Wolpert EB, Giger KE and Morgan HE (1971) Regulation of protein synthesis in heart muscle. 3 . Effect of anoxia on protein synthesis. J. Biol. Chem. 246: 2171-2178

7. Cooper HK, Zalewska T, Kawakami S, Hossmann KA and Kleihues P (1977) The effect of ischaemia and recirculation on protein synthesis in the rat brain. J. Neurochem. 28: 929-934

8. Burda J, Martin ME, Gottlieb M, Chavko M, Marsala J, Alcazar A, Pavlon M, Fando JL and Salinas M (1998) The intraischemic and early reperfusion changes of protein synthesis in the rat brain. elF-2 alpha kinase activity and role of initiation factors elF-2 alpha and elF-4E. J. Cereb. Blood Flow Metab. 18: $59-66$

9. Mengesdorf T, Proud CG, Mies G and Paschen W (2002) Mechanisms underlying suppression of protein synthesis induced by transient focal cerebral ischemia in mouse brain. Exp. Neurol. 177: 538-546

10. Althausen S, Mengesdorf T, Mies G, Olah L, Nairn AC, Proud CG and Paschen W (2001) Changes in the phosphorylation of initiation factor elF-2alpha, elongation factor eEF-2 and p70 S6 kinase after transient focal cerebral ischaemia in mice. J. Neurochem. 78: 779-787

11. Garcia L, Burda J, Hrehorovska M, Burda R, Martin ME and Salinas M (2004) Ischaemic preconditioning in the rat brain: effect on the activity of several initiation factors, Akt and extracellular signal-regulated protein kinase phosphorylation, and GRP78 and GADD34 expression. J. Neurochem. 88: 136-147

12. Garcia L, O'Loghlen A, Martin ME, Burda J and Salinas M (2004) Does phosphorylation of eukaryotic elongation factor eEF2 regulate protein synthesis in ischemic preconditioning? J. Neurosci. Res. 77: 292-298

13. Martin de la Vega C, Burda J, Nemethova M, Quevedo C, Alcazar A, Martin ME, Damelisova V, Fando JL and Salinas M (2001) Possible mechanisms involved in the down-regulation of translation during transient global ischaemia in the rat brain. Biochem. J. 357: 819-826

14. Horman S, Beauloye C, Vertommen D, Vanoverschelde JL, Hue L and Rider $\mathrm{MH}$ (2003) Myocardial ischemia and increased heart work modulate the phosphorylation state of eukaryotic elongation factor-2. J. Biol. Chem. 278: 41970-41976

15. Wells SE, Hillner PE, Vale RD and Sachs AB (1998) Circularization of mRNA by eukaryotic translation initiation factors. Mol. Cell 2: 135-140

16. Gingras A-C, Raught B and Sonenberg N (1999) elF4 initiation factors: effectors of mRNA recruitment to ribosomes and regulators of translation. Annu. Rev. Biochem. 68: 913-963

17. Schneider RJ and Mohr I (2003) Translation initiation and viral tricks. Trends Biochem. Sci. 28: 130-136 
18. Ueda $T$, Watanabe-Fukunaga $R$, Fukuyama $H$, Nagata $S$ and Fukunaga $R$ (2004) Mnk2 and Mnk1 are essential for constitutive and inducible phosphorylation of eukaryotic initiation factor $4 \mathrm{E}$ but not for cell growth or development. Mol. Cell. Biol. 24: 6539-6549

19. Morley SJ and Naegele S (2002) Phosphorylation of eukaryotic initiation factor (eIF) $4 \mathrm{E}$ is not required for de novo protein synthesis following recovery from hypertonic stress in human kidney cells. J. Biol. Chem. 277: 32855-32859

20. Clemens MJ, Bushell M, Jeffrey IW, Pain VM and Morley SJ (2000) Translation initiation factor modifications and the regulation of protein synthesis in apoptotic cells. Cell Death Differ. 7: 603-615

21. Tinton SA and Buc-Calderon PM (1999) Hypoxia increases the association of $4 \mathrm{E}$-binding protein 1 with the initiation factor $4 \mathrm{E}$ in isolated rat hepatocytes. FEBS Lett. 446: 55-59

22. Hershey JWB and Merrick WC (2000) Pathway and mechanism of initiation of protein synthesis. In Translational Regulation of Gene Expression, Hershey JWB, Mathews MB, Sonenberg N (eds) (Cold Spring Harbor, NY: Cold Spring Harbor Laboratory Press) pp. 33-88

23. Neumar RW, DeGracia DJ, Konkoly LL, Khoury JI, White BC and Krause GS (1998) Calpain mediates eukaryotic initiation factor $4 G$ degradation during global brain ischemia. J. Cereb. Blood Flow Metab. 18: 876-881

24. Morley SJ, Coldwell MJ and Clemens MJ (2005) Initiation factor modifications in the preapoptotic phase. Cell Death Differ. 12: $571-584$

25. Browne GJ and Proud CG (2002) Regulation of peptide-chain elongation in mammalian cells. Eur. J. Biochem. 269: 5360-5368

26. Browne GJ and Proud CG (2004) A novel mTOR-regulated phosphorylation site in elongation factor 2 kinase modulates the activity of the kinase and its binding to calmodulin. Mol. Cell. Biol. 24: 2986-2997

27. Wang X, Li W, Williams M, Terada N, Alessi DR and Proud CG (2001) Regulation of elongation factor 2 kinase by $p 90$ (RSK1) and p70 S6 kinase. EMBO J. 20: 4370-4379

28. Browne GJ, Finn SG and Proud CG (2004) Stimulation of the AMP-activated protein kinase leads to activation of eukaryotic elongation factor 2 kinase and to its phosphorylation at a novel site, serine 398. J. Biol. Chem. 279: 12220-12231

29. Bolster DR, Crozier SJ, Kimball SR and Jefferson LS (2002) AMP-activated protein kinase suppresses protein synthesis in rat skeletal muscle through down-regulated mammalian target of rapamycin (mTOR) signaling. J. Biol. Chem. 277: 23977-23980

30. Bolster DR, Kubica N, Crozier SJ, Williamson DL, Farrell PA, Kimball SR and Jefferson LS (2003) Immediate response of mammalian target of rapamycin (mTOR)-mediated signaling following acute resistance exercise in rat skeletal muscle. J. Physiol. 553: 213-220

31. Rowland RT, Meng X, Cleveland JC, Meldrum DR, Harken AH and Brown JM (1997) Cardioadaptation induced by cyclic ischemic preconditioning is mediated by translational regulation of de novo protein synthesis. J. Surg. Res. 71: 155-160
32. Fujio Y, Nguyen T, Wencker D, Kitsis RN and Walsh K (2000) Akt promotes survival of cardiomyocytes in vitro and protects against ischemia-reperfusion injury in mouse heart. Circulation 101: 660-667

33. Mockridge JW, Marber MS and Heads RJ (2000) Activation of Akt during simulated ischemia/reperfusion in cardiac myocytes. Biochem. Biophys. Res. Commun. 270: 947-952

34. Martin ME, Munoz FM, Salinas M and Fando JL (2000) Ischaemia induces changes in the association of the binding protein 4E-BP1 and eukaryotic initiation factor (eIF) 4G to elF4E in differentiated PC12 cells. Biochem. J. 351: 327-334

35. Byrd MP, Zamora M and Lloyd RE (2002) Generation of multiple isoforms of eukaryotic translation initiation factor $4 \mathrm{Gl}$ by use of alternate translation initiation codons. Mol. Cell. Biol. 22: 4499-4511

36. Cuesta R, Laroia G and Schneider RJ (2000) Chaperone Hsp27 promotes disassembly of translation cap initiation complex during heat shock. Genes Dev. 14: 1460-1470

37. Bialik S, Geenen DL, Sasson IE, Cheng R, Horner JW, Evans SM, Lord EM, Koch CJ and Kitsis RN (1977) Myocyte apoptosis during acute myocardial infarction in the mouse localizes to hypoxic regions but occurs independently of p53. J. Clin. Invest. 100: 1363-1372

38. Neumar RW, Xu YA, Gada H, Guttmann RP and Siman R (2003) Cross-talk between calpain and caspase proteolytic systems during neuronal apoptosis. J. Biol. Chem. 278: 14162-14167

39. Zhang C, Siman R, Xu YA, Mills AM, Frederick JR and Neumar RW (2002) Comparison of calpain and caspase activities in the adult rat brain after transient forebrain ischemia. Neurobiol. Dis. 10: 289-305

40. Bushell M, McKendrick L, Janicke RU, Clemens MJ and Morley SJ (1999) Caspase- 3 is necessary and sufficient for cleavage of protein synthesis eukaryotic initiation factor $4 G$ during apoptosis. FEBS Lett. 451: 332-336

41. Morley SJ (2001) The regulation of elF4F during cell growth and cell death. Prog. Mol. Subcell. Biol. 27: 1-37

42. Bushell M, Poncet D, Marissen WE, Flotow H, Lloyd RE, Clemens MJ and Morley SJ (2000) Cleavage of polypeptide chain initiation factor elF4GI during apoptosis in lymphoma cells: characterization of an internal fragment generated by caspase-3-mediated cleavage. Cell Death Differ. 7: 628-636

43. Coldwell MJ, Hashemzadeh-Bonehi L, Hinton TM, Morley SJ and Pain VM (2004) Expression of fragments of translation initiation factor elF4GI reveals a nuclear localization signal within the $\mathrm{N}$-terminal apoptotic cleavage fragment N-FAG. J. Cell Sci. 117: 2545-2555

44. Kedersha $N$ and Anderson $P$ (2002) Stress granules: sites of mRNA triage that regulate mRNA stability and translatability. Biochem. Soc. Trans. 30: 963-969

45. Koumenis C, Naczki C, Koritzinsky M, Rastani S, Diehl A, Sonenberg N, Koromilas A and Wouters BG (2002) Regulation of protein synthesis by hypoxia via activation of the endoplasmic reticulum kinase PERK and phosphorylation of the translation initiation factor elF2alpha. Mol. Cell. Biol. 22: 7405-7416 